\title{
SYNTHESIS OF POLY (BIBENZIMIDAZOLE-P-PHENYL- BENZOBISOXAZOLE)
}

\author{
YANHUA LU ${ }^{a, b}$, JIANMIN CHEN ${ }^{a,{ }^{*}}$, HAIXIA CUI ${ }^{a}$, HUIDI ZHOU $^{a}$ \\ ${ }^{a}$ State Key Laboratory of Solid Lubrication, Lanzhou Institute of Chemical Physics, \\ Chinese Academy of Sciences, Lanzhou 730000, China
}

(Received: July 22, 2008 - Accepted: April 29, 2009)

\begin{abstract}
A diacid monomer of benzobisoxazole 2, 6-di(p-phenylene-carboxylic) acid (BBODPA) was synthesized in a simple procedure, and characterized by means of FTIR, ${ }^{1} \mathrm{H}$ NMR and ${ }^{13} \mathrm{C}$ NMR. The resulting BBODPA was polymerized with 3, 3'-diaminobenzidine tetrahydrochloride (DAB) to prepare poly (bibenzimidazolep-phenyl-benzobisoxazole) (PBBIBBO) in polyphosphoric acid. The inherent viscosities values of PBBIBBO indicated that it was a kind of high molecular weight polymer. The structure of PBBIBBO was confirmed by ${ }^{1} \mathrm{H}$ NMR, ${ }^{13} \mathrm{C}$ NMR and FTIR. Thermal properties and dissolubility of PBBIBBO were also investigated. These results showed that PBBIBBO exhibited good thermal stability.
\end{abstract}

Key words: Copolymer, polybenzimidazole, polybenzoxazole, thermal stability

\section{INTRODUCTION}

Polybenzimidazole (PBI) and polybenzoxazole (PBO) have received considerable attention since 1960 s, due to their chemical resistance, thermal stability and good mechanical properties at high temperature. ${ }^{1,2}$ Fibers, ${ }^{3,4}$ foams, ${ }^{5,6}$ membrane $^{7,8}$ and structural materials ${ }^{9,10}$ of PBI and PBO have been extensively investigated. Melt polycondensation ${ }^{2,11}$ and solution polycondensation ${ }^{12-16}$ have been frequently used to synthesize PBI and PBO. Attempts have been made to combine polybenzimidazole with polybenzoxazole, in order to obtain more thermal stable and tractable polymers. For example, copolymers containing both PBI and PBO segments have been prepared. ${ }^{17,18}$ The authors claimed that phase separation reaction would not easily take place compared with the solution mixture of polybenzimidazole and polybenzoxazole.

In the present study, homopolymer of poly (bibenzimidazole-p-phenylbenzobisoxazole) (PBBIBBO) was synthesized. Benzobisoxazole 2, 6-di(pphenylene-carboxylic) acid (BBODPA) was firstly synthesized using 4, 6-Diaminoresorcinol Dichloride (DAR) and paraphthaloyl chloride (PPC), as described in Scheme 1. Then the resulting BBODPA polymerized with 3, 3'diaminobenzidine tetrahydrochloride (DAB) in polyphosphoric acid (PPA) to prepare PBBIBBO (Scheme 2). The compound of PBBIBBO which combined both benzoxazole groups and benzimidazole groups on the polymer chain was expected to find a place in preparing fiber and membrane materials.

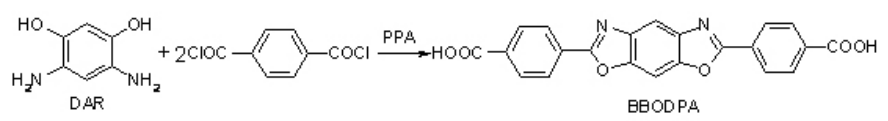

Scheme 1. Synthesis of BBODPA.

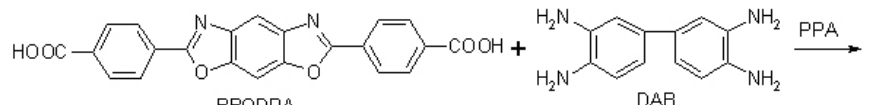<smiles></smiles>

Scheme 2. Synthesis of PBBIBBO.

\section{EXPERIMENTAL}

Materials

DAB and DAR were prepared by the procedures of Herward and Marvel. ${ }^{2}$ Benzidine, $\mathrm{m}$-phenylene diamine, paraphthaloyl chloride, polyphosphoric acid, phosphorus pentoxide and acetic acid were obtained from commercial sources and used as received.

Methods

A Bruker AV-400 type superconducting magnetic resonance spectrometer (400 MHz, using $\mathrm{H}_{2} \mathrm{SO}_{4}-\mathrm{d}_{2}$ as solvents) was performed to record the ${ }^{1} \mathrm{H}$-nuclear magnetic resonance spectra $\left({ }^{1} \mathrm{H} \mathrm{NMR}\right)$ and ${ }^{13} \mathrm{C}$-nuclear magnetic resonance spectra $\left({ }^{13} \mathrm{C}\right.$ NMR). Fourier transform infrared (FTIR) spectra were obtained with a Bruker IFS66v/S Fourier transformation spectrophotometer ( $\mathrm{KBr}$ discs). Thermal gravimetric analysis (TGA) was performed using a STA449C device (NETZSCH, Germany). The samples for TGA were placed in $75 \mu \mathrm{Al}_{2} \mathrm{O}_{3}$ pans and heated from $25{ }^{\circ} \mathrm{C}$ to $1000{ }^{\circ} \mathrm{C}$ at a heating rate of $10{ }^{\circ} \mathrm{C} / \mathrm{min}$, under a constant $\mathrm{N}_{2}$ flow of $20 \mathrm{ml} / \mathrm{min}$. Inherent viscosities $\left(\eta_{\mathrm{inh}}=\ln \eta_{\mathrm{ra}} / \mathrm{C}\right)$ of polymers were determined for solution of $0.5 \mathrm{~g} / \mathrm{dl}$ in $\mathrm{H}_{2} \mathrm{SO}_{4}(98 \%)$ at $30{ }^{\circ} \mathrm{C}$ using a Ubbelohde viscometer.

Synthetic procedure for the monomer of BBODPA

In a three necked $2000 \mathrm{ml}$ round bottom flask equipped with a mechanical stirrer and nitrogen inlet was placed $500 \mathrm{ml}$ of PPA, $54.46 \mathrm{~g}(0.40 \mathrm{~mol})$ of PPC and $2.5 \mathrm{~g}$ of $\mathrm{SnCl}_{2} \cdot 2 \mathrm{H}_{2} \mathrm{O}$. In to this flask $49.82 \mathrm{~g}(0.20 \mathrm{~mol})$ of DAR $\left(\mathrm{C}_{6} \mathrm{H}_{8} \mathrm{~N}_{2} \mathrm{O}_{2} \cdot 2 \mathrm{HCl} \cdot 2 \mathrm{H}_{2} \mathrm{O}\right)$ was added gradually and dissolved to prevent the carry-over of the reactant by the emitting $\mathrm{HCl}$ under $105^{\circ} \mathrm{C}$. Once that the addition was finished the temperature was raised to $200{ }^{\circ} \mathrm{C}$ and kept at this temperature for $7 \mathrm{~h}$. The product was isolated by pouring the hot solution into water, washing with water, dipping in dilute $\mathrm{KOH}$ overnight and drying in a vacuum oven at $50{ }^{\circ} \mathrm{C}$ for $24 \mathrm{~h}$. The yield of BBODPA was $95 \%$.

\section{Preparation of $P B B I B B O$}

A $2000 \mathrm{ml}$ three-necked flask equipped with a stirrer and nitrogen inlet was charged with $1000 \mathrm{ml}$ of PPA $\left(\mathrm{P}_{2} \mathrm{O}_{5} \geq 85 \%\right)$ and $2 \mathrm{~g}$ of $\mathrm{SnCl}_{2} \cdot 2 \mathrm{H}_{2} \mathrm{O}$. The flask was then placed into a silicone oil bath preheated to $105^{\circ} \mathrm{C}$. Into this flask, $40.8035 \mathrm{~g}(0.1030 \mathrm{~mol})$ of DAB $\left(\mathrm{C}_{12} \mathrm{~N}_{4} \mathrm{H}_{14} \cdot 4 \mathrm{HCl} \cdot 2 \mathrm{H}_{2} \mathrm{O}\right)$ was added gradually and dissolved to prevent the carry-over of the reactant by the emitting $\mathrm{HCl}$. To the resulting mixed solution $43.60 \mathrm{~g}(0.10 \mathrm{~mol})$ of BBODPA $\left(\mathrm{C}_{22} \mathrm{H}_{12} \mathrm{~N}_{2} \mathrm{O}_{6} \cdot 2 \mathrm{H}_{2} \mathrm{O}\right)$ were added. Under a thin stream of nitrogen, the solution was heated at 200 ${ }^{\circ} \mathrm{C}$ for $12 \mathrm{~h}$. The polymeric target product was isolated by pouring the hot solution into water, washing with water by decantation, dipping in dilute $\mathrm{KOH}$ overnight, washing thoroughly with water and $\mathrm{CH}_{3} \mathrm{OH}$, and drying in a vacuum oven at $50^{\circ} \mathrm{C}$, generating $46.42 \mathrm{~g}$ of PBBIBBO.

\section{RESULTS AND DISCUSSION}

Monomer syntheses

We have attempted to use benzobisoxazole 2, 6-di carboxylic acid (BBODPA) (Figure 1) as the monomer to synthesize PBBIBBO. However, BBODPA decomposed under $140{ }^{\circ} \mathrm{C}$. Leonard and Kaimierczak suggested that the 2-carboxyl acid in benzoxazole or benzimidazole molecular were thermally unstable. ${ }^{19}$ These results agreed with our research. It seems that the carboxylic acid on the 2-benzoxazole or 2-benzimidazole was thermally unstable. The phenyl carboxylic acid like BBODPA was more thermally stable and selected as the monomer to synthesize the PBBIBBO. 
$\mathrm{HOOC}-(\mathrm{C} / \mathrm{COOH}$

(a) BBODA

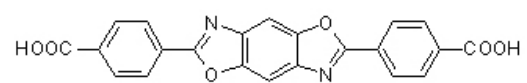

(b) BQODPA
Fig. 1. Molecular structures of (a) BBODPA and (b) BBODPA.

The monomer of BBODPA was prepared by solution method, as depicted in Scheme 1. The resulting BBODPA is confirmed by FTIR and ${ }^{1} \mathrm{H}$ NMR and ${ }^{13} \mathrm{C}$ NMR. Figure 2 shows the FTIR spectrum of BBODPA. It is observed that a broad $\mathrm{O}-\mathrm{H}$ stretch is presented at $2000-3700 \mathrm{~cm}^{-1},{ }^{20}$ carbonyl group at 1688 $\mathrm{cm}^{-1}\left(\mathrm{C}=\mathrm{O}\right.$ acidic, stretching), asymmetric $\mathrm{C}=\mathrm{C}$ at $1610 \mathrm{~cm}^{-1}(\mathrm{C}=\mathrm{C}$, stretching) and $\mathrm{CN}$ of benzoxazole at $1268 \mathrm{~cm}^{-1}(\mathrm{C}=\mathrm{N}$, stretching $)$.

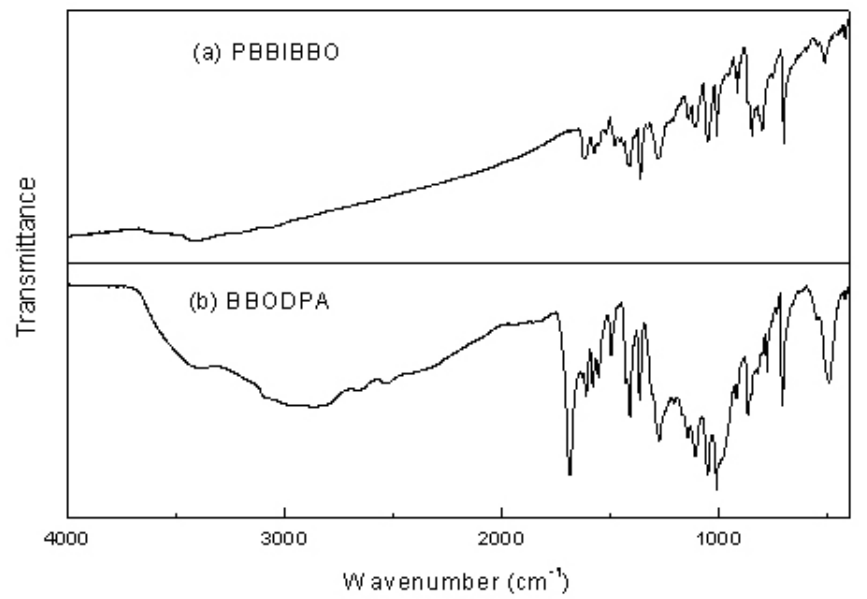

Fig. 2. FTIR spectra of (a) PBBIBBO and (b) BBODPA.

The ${ }^{1} \mathrm{H}$ NMR spectrum of BBODPA was obtained in deuterated sulfuric acid. The aromatic proton was observed at $7.9-8.5 \mathrm{ppm}$. It should be noted that BBODPA was almost insoluble in DMSO and $\mathrm{CHCl}_{3} . \mathrm{H}_{2} \mathrm{SO}_{4}-\mathrm{d}_{2}$ was used as solvent to acquire the ${ }^{1} \mathrm{H}$ NMR spectrum. The proton of carboxylic acid $(\mathrm{COO}-\mathrm{H})$ was not observed, which was attributed the proton-exchange between $\mathrm{H}_{2} \mathrm{SO}_{-}-\mathrm{d}_{2}$ and carboxylic acid group of BBODPA.

${ }^{1} \mathrm{H}$ NMR $\left(\mathrm{H}_{2} \mathrm{SO}_{4}-\mathrm{d}_{2}, \delta \mathrm{ppm}\right.$ ): 7.95 (benzobisoxazole, $1 \mathrm{H}$ ), 8.20 (benzene, $2 \mathrm{H}), 8.39$ (benzene, $2 \mathrm{H}), 10.5\left(\mathrm{H}_{2} \mathrm{SO}_{4}\right.$, solvent).

${ }^{13} \mathrm{C}$ NMR $\left(\mathrm{H}_{2} \mathrm{SO}_{4}-\mathrm{d}_{2}, \delta \mathrm{ppm}\right): 111.0,120.5,125.3,127.4,128.4,129.4$, $145.3,163.3,170.4$.

\section{Polymer synthesis}

The obtained PBBIBBO was a high molecular weight polymer, as evidenced from its inherent viscosities $\left(\eta_{\text {inh }}\right)$ values of $4.2 \mathrm{dl} / \mathrm{g}$ for the polymer. Figure 2 show the FTIR spectrum of PBBIBBO. As can be seen, there is no strong O-H stretch at $2000-3700 \mathrm{~cm}^{-1}$ and carbonyl group at $1689 \mathrm{~cm}^{-1}$, indicating that complete closure of the oxazole rings in the polymerization has been achieved. The characteristic peaks of BBODPA and PBBIBBO in FTIR spectra are listed in Table $1 .{ }^{21}$

Table 1. Summary of FTIR spectra of BBODPA and PBBIBBO.

\begin{tabular}{|l|l|l|}
\hline \multirow{2}{*}{ Assignment } & \multicolumn{2}{|c|}{ Frequency $\left(\mathrm{cm}^{-1}\right)$} \\
\cline { 2 - 3 } & BBODPA & PBBIBBO \\
\hline $\mathrm{C}=\mathrm{O}$ stretch & 1689 & \\
\hline Asym. C=C stretch & 1610 & 1618 \\
\hline Hetero-ring stretch (vs) & 1498 & 1480 \\
\hline $1,4-\mathrm{C}_{6} \mathrm{H}_{4}$ & 1409 & 1413 \\
\hline Hetero-ring stretch (vs) & 1365 & 1364 \\
\hline Hetero-ring 'breathing' (vs) & 1108 & 1110 \\
\hline $1,2,4,5-\mathrm{C}_{6} \mathrm{H}_{2}(\mathrm{~s})$ & 864 & 848 \\
\hline
\end{tabular}

The ${ }^{1} \mathrm{H}$ NMR spectrum of PBBIBBO was obtained in deuterated sulfuric acid. The proton of aromatic was observed at $7.6-8.5 \mathrm{ppm}$. The proton of benzimidazole was not observed, like that of BBODPA, which was attributed the proton-exchange between $\mathrm{H}_{2} \mathrm{SO}_{4}-\mathrm{d}_{2}$ and benzimidazole moiety.

The characterization by ${ }^{1} \mathrm{H}$ NMR, ${ }^{2} \mathrm{C}$ NMR and FTIR confirmed that the resulting $\mathrm{PBBIBBO}$ have the expected chemical structures.

${ }^{1} \mathrm{H}$ NMR $\left(\mathrm{H}_{2} \mathrm{SO}_{4}-\mathrm{d}_{2} ; \delta \mathrm{ppm}\right): 7.63$ (benzobisoxazole, $\left.2 \mathrm{H}\right), 7.71$ (benzimidazole, 1H), 8.09 (benzene, 4H), 8.27 (benzimidazole, 1H), 8.42 (benzimidazole, $1 \mathrm{H}), 10.5\left(\mathrm{H}_{2} \mathrm{SO}_{4}\right.$, solvent).

${ }^{13} \mathrm{C}$ NMR $\left(\mathrm{H}_{2} \mathrm{SO}_{4}-\mathrm{d}_{2} ; \delta\right.$ ppm $): 110.8,114.6,115.7,120.5,122.9,128.0$, 130.6, 131.0, 134.5, 137.2, 139.4, 152.8, 162.7 .

\section{Thermal properties}

The weight vs. temperature curves for PBBIBBO and BBODPA are shown in Figure 3. BBODPA displayed three-step thermal degradation processes, namely, desorption of water, decomposition of carbonyl group and aromatic group. The initial 6-8 wt.\% weight loss of BBODPA below $145{ }^{\circ} \mathrm{C}$ is mainly due to the volatilizing of water, which corresponds to about 2 crystal water molecules per unit of BBODPA $\left(\mathrm{C}_{22} \mathrm{H}_{12} \mathrm{~N}_{2} \mathrm{O}_{6} \cdot 2 \mathrm{H}_{2} \mathrm{O}\right)$. The degradation of carbonyl group of BBODPA begins at $200{ }^{\circ} \mathrm{C}$ and the decomposition of aromatic group begins at $410{ }^{\circ} \mathrm{C}$.

It can be observed in Figure 3 that the initial decomposition temperature of PBBIBBO is about $590{ }^{\circ} \mathrm{C}$. When temperature reached $770{ }^{\circ} \mathrm{C}$, there is still about $50 \mathrm{wt} . \%$ of residual left. These values show that PBBIBBO has reasonably good thermal stability. It is also shown that PBBIBBO exhibit better thermal stability than its monomer of BBODPA and DAB.

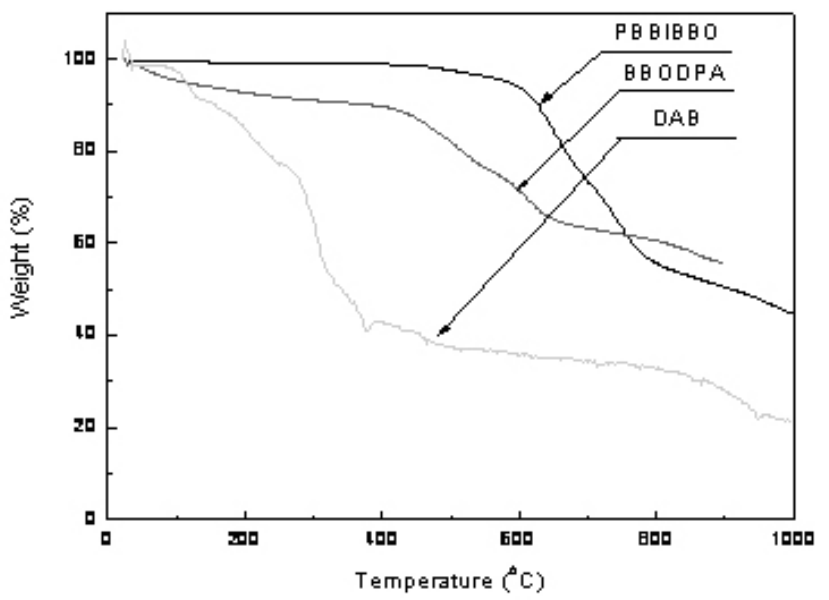

Fig. 3. TGA results of (a) PBBIBBO and (b) BBODPA.

Dissolubility of BBODPA and PBBIBBO was examined in different solvents and the results are summarized in Table 2. They are soluble in sulfuric acid. BBODPA is insoluble in other hot solvents except in hot DMF. PBBIBBO is soluble in hot DMF, DMAc and NMP

Table 2. Dissolubility of BBODPA and PBBIBBO (++: soluble at room temperature; soluble in hot; -: insoluble).

\begin{tabular}{|l|c|c|c|c|c|}
\hline & $\mathrm{H}_{2} \mathrm{SO}_{4}$ & DMSO & DMF & DMAc & NMP \\
\hline BBODPA & ++ & - & + & - & - \\
\hline PBBIBBO & ++ & - & + & + & + \\
\hline
\end{tabular}

\section{CONCLUSIONS}

The diacid monomer of BBODPA was synthesized from DAR and PPC, and was characterized in this work. BBODPA was then used as monomers for the synthesis of new PBBIBBO.

Investigation of dissolubility of PBBIBBO showed that it was insoluble in polar aprotic solvents but soluble in $\mathrm{H}_{2} \mathrm{SO}_{4}$ at room temperature. Thermal stability of BBODPA and PBBIBBO were also studied with TGA. The result showed temperature of $5 \%$ weight loss of PBBIBBO stayed in the range of 590$600^{\circ} \mathrm{C}$, indicating good thermal stabilities of the polymer. 


\section{ACKNOWLEDGEMENTS}

The authors are grateful to the National Natural Science Foundation of China (Grant No. 50575217), the program of "973" (Grant No. 20070B607601) and the Innovative Group Foundation from NSFC (Grant No. 50421502) for financial support.

\section{REFERENCES}

1. K. Tamargo-Martinez, S. Villar-Rodil, J. I. Paredes, Polym. Degrad. Stabil. 86(2), 263, (2004).

2. H. Vogel, C. S. Marvel, J. Polym. Sci. 50(154), 511, (1961).

3. T. S. Chung, Z. L. Xu, J. Membrane Sci. 147(1), 35, (1998).

4. K. Y. Wang, T. S. Chung, J. J. Qin, J. Membrane Sci. 300(1-2), 6, (2007).

5. H. Sun, J. E. Mark, S. C. Tan, N. Venkatasubramanian, M. D. Houtz, F. E. Arnold, C. Y. C. Lee, Polymer. 46(17), 6623, (2005).

6. J. S. Letinski, G. E. Gillberg-LaForce, U. S. Patent. 4,810,730, (1989).

7. J. Zhang, Y. Tang, C. Song, J. Zhang, J. Power Sources. 172(1), 163, (2007).

8. C. Pan, Q. Li, J. O. Jensen, R. He, L. N. Cleemann, M. S. Nilsson, N. J. Bjerrum, Q. Zeng, J. Power Sources. 172(1), 278, (2007).
9. B. C. Ward, E. Alvarez, R. S. Blake, U. S. Patent. 4,814,530, (1989).

10. J. S. Letinski, U. S. Patent. 4,717,619, (1988).

11. K. C. Brinker, I. M. Robinson, U. S. Patent. 2,895,948, (1959).

12. Y. Iwakura, K. Uno, Y. Imai, J. Polym. Sci. Pol. Chem. 2(6), 2605, (1964).

13. A. Banihashemi, F. Atabaki, Eur. Polym. J. 38, 2119, (2002).

14. J. Lobato, P. Canizares, M.A. Rodrigo, J. J. Linares, G. Manjavacas, $J$. Membr. Sci. 280(1-2), 351, (2006).

15. H. M. Gajiwala, R. Zand, Polymer. 41(6), 2009, (2000).

16. J. Li, X. Chen, X. Li, H. Cao, H. Yu, Y. Huang, Polym. Int. 55(4), 456, (2006).

17. B. Gordon, R. J. Kumpf, P. C. Painter, J. Polym. Sci. Pol. Chem. 26(7), $1689,(1988)$

18. W. J. Harris, W. F. Hwang, U. S. Patent. 5,098,985, (1992)

19. N. J. Leonard, F. Kazmierczak, A. Z. Rykowski, J. Org. Chem. 52(13), 2933, (1987)

20. J. H. Chang, K. M. Park, S. M. Lee, J. B. Oh, J. Polym. Sci. Pol. Phys. 38(19), 2537, (2000).

21. P. Guo, S. Wang, P. Wu, Z. Han, Polymer. 45(6), 1885, (2004). 